\title{
Spatial and Temporal Characteristics of Drought and Flood in Quanzhou Based on Standardized Precipitation Index (SPI) in Recent 55 Years
}

\author{
Dehe Liu', Jingfei You², Qijie Xie², Yuanyuan Huang3, Huajun Tong2 \\ ${ }^{1}$ Yongchun County Meteorological Bureau of Fujian Province, Yongchun, China \\ ${ }^{2}$ Quanzhou Meteorological Bureau of Fujian Province, Quanzhou, China \\ ${ }^{3}$ Nan'an Meteorological Bureau of Fujian Province, Nan'an, China \\ Email:99308518@qq.com
}

How to cite this paper: Liu, D.H., You, J.F., Xie, Q.J., Huang, Y.Y. and Tong, H.J. (2018) Spatial and Temporal Characteristics of Drought and Flood in Quanzhou Based on Standardized Precipitation Index (SPI) in Recent 55 Years. Journal of Geoscience and Environment Protection, 6, 25-37. https://doi.org/10.4236/gep.2018.68003

Received: July 2, 2018

Accepted: July 31, 2018

Published: August 3, 2018

Copyright $\odot 2018$ by authors and Scientific Research Publishing Inc. This work is licensed under the Creative Commons Attribution International License (CC BY 4.0).

http://creativecommons.org/licenses/by/4.0/

\section{(c) (i) Open Access}

\begin{abstract}
To analyze the characteristics of drought and flood variations in Quanzhou during recent 55 years, the standardized precipitation index (SPI) and Empirical Orthogonal Function (EOF) and Rotated Empirical Orthogonal Function (REOF) were calculated by using the monthly precipitation data from 6 meteorological bureaus across Quanzhou for 1960-2014. Results showed that: 1) During 1960-2014, the drought and flood showed Periodic variation characteristics in Quanzhou, the specific period of frequent drought was 1963-1972, 1977-1986 and 2009-2011, and the specific period of frequent flood was 1961-1962, 1972-1975, 1990-1992 and 1997-2007; the drought and flood did not have significant tendency of variation in Spring and Summer, and the drought and flood showed a non-significant downward trend in Autumn and Winter. 2) The drought and flood variation had relatively consistent trend in Quanzhou, but there was a big difference on the northwest mountainous area, the middle semi-mountainous area and the southeast coast area in some periods. 3) The precipitation cell and distribution in every season were Nan'an and Anxi, but there was a big difference in rainfall less area: it was Yongchun and Dehua in Spring, Chongwu and Jinjiang in Summer, Chongwu in Autumn, Dehua and Chongwu in Winter.
\end{abstract}

\section{Keywords}

Standardized Precipitation Index, Drought and Flood, Empirical Orthogonal Function (EOF), Rotated Empirical Orthogonal Function (REOF) 


\section{Introduction}

The loss caused by meteorological disasters is huge, and in meteorological disasters, the effects of droughts and floods are the most serious [1]. Located on the southeastern coast of Fujian Province, Quanzhou is a subtropical marine monsoon climate. It is located in the middle section of the Jidong Mountains and in the middle of the hilly plain on the southeast coast of Fujian. The west is the main part of Daiyunshan. It is adjacent to the Taiwan Strait in the south, facing the mountains and the sea. The terrain is low in the northwest and high in the southeast, and has the topography and landforms of mountains, hills and coastal plains. The regional climate characteristics are obvious. The intensity of the monsoon and its appearance sooner or later have a greater impact on the precipitation time and regional distribution. Drought and flood disasters often occur and it is one of the most severe meteorological disasters in Quanzhou. It has become an important factor that restricts socio-economic sustainable development in Quanzhou.

At present, the commonly used indicators of droughts and floods include precipitation anomaly $(\mathrm{Pa})$, Palmer drought index (PDSI), soil relative humidity index, standardized precipitation index (SPI), Z index, and integrated meteorological drought index (CI). Many scholars at home and abroad have comparatively analyzed the effects of different indexes on monitoring drought events. The SPI index based on precipitation data not only has the advantages of simple calculation and multiple time scales, but also can compare droughts and floods in different spaces and has good stability. In extreme cases, it is superior to the widely used $\mathrm{Z}$ index in the country and has been widely used in drought monitoring [2] [3] [4] [5]. Livada and Assimakopoulos [6] used the rainfall data from the Greek meteorological station to calculate the SPI values in Greece and analyzed the temporal and spatial changes of the drought in the region. Wu et al. [7] [8] showed that the longer the precipitation record time, the more reliable the SPI results. Under arid climate conditions, more attention should be paid to the duration of drought, not just the drought intensity. Yuan Wenping et al. [9] used SPI and Z index to study wet and dry climate events in different regions of China. He believed that SPI has superior stability in calculation compared with Z index. It has a good monitoring effect on extreme dry and wet climate events and can be used for water resources assessment in China and drought monitoring at different time scales. Therefore, this paper uses the monthly precipitation data from stations in Quanzhou City from 1960 to 2014, and uses the standardized precipitation index (SPI) to analyze the spatial and temporal distribution characteristics of droughts and floods in Quanzhou. It is not common to introduce the above studies into the Quanzhou area. It is expected to provide a scientific basis for the monitoring and evaluation of droughts and floods, prevention and mitigation of droughts and floods, and rational use of water resources. 


\section{Data and Methods}

\subsection{Research Data}

The data used by the Institute is the monthly precipitation data from 6 regular weather stations in Quanzhou during 1960-2014. In order to ensure the integrity and continuity of the data, the monthly precipitation data from Anxi Station in January, August, and August in January 1968 and January 1971 were used to interpolate the monthly precipitation data from the Nan'an Station with the best correlation.

\subsection{Research Methods}

The Standardized Precipitation Index (SPI) was proposed by McKee et al. [10]. Only a relatively long period of precipitation (generally more than 30 years) is needed to calculate the drought index at different time scales. It is applicable to drought monitoring and assessment on a monthly scale. The formula is [11] [12]:

$$
S P I=S \frac{t-\left(c_{2} t+c_{1}\right) t+c_{0}}{\left[\left(d_{3} t+d_{2}\right) t+d_{1}\right] t+1.0}
$$

In the formula, $t=\sqrt{\ln \frac{1}{g(x)^{2}}}, g(x)$ is the probability distribution of precipitation associated with the $\Gamma$ function; $x$ is the sample of precipitation; $S$ is the positive and negative coefficient of probability density.

When $g(x)>0.5, \mathrm{~S}=1$; when $g(x) \leq 0.5, S=-1 . g(x)$ is calculated from the probability density integral formula of the $\Gamma$ distribution function:

$$
g(x)=\frac{1}{\beta^{\alpha} \Gamma(\alpha)_{0}} \int_{0}^{x} x^{\alpha-1} \mathrm{e}^{-\frac{x}{\beta}} \mathrm{d} x, x>0
$$

In the formula, $\alpha$ and $\beta$ are the shape parameters and scale parameters of the $\Gamma$ distribution function, respectively. $c_{0}, c_{1}, c_{2}$ and $d_{1}, d_{2}, d_{3}$ are the calculation parameters of the simplified approximate solution formula for the conversion of the $\Gamma$ distribution function to the cumulative frequency, where $c_{0}=2.515517, c_{1}=0.802853, c_{2}=0.010328, d_{1}=1.432788, d_{2}$ $=0.189269, d_{3}=0.001308$.

SPI has the characteristics of multiple time scales $(1,3,6,12,24,48$ months, etc.). For example, the SPI of December time scale represents the standard deviation of December precipitation. The SPI of 3 months time scale in December represents the standard deviation of precipitation in October-December. The December 12-month time scale SPI represents the standard deviation of January-December precipitation. This article mainly analyzes the 12 -month and 3-month time scale SPI. Because 12-month time scale SPI can more clearly reflect the stage changes of drought and flood, and 3-month time scale SPI can reflect the seasonal drought, it is closely related to agricultural drought. The drought classification was graded according to the drought level criteria such as 
Mckee [10], and the degree of drought was added according to the drought level criteria (Table 1).

The empirical orthogonal function (EOF) and the rotational empirical orthogonal function (REOF) can convert the original multiple related indexes to a few new and independent comprehensive indexes without losing or losing the original information. Therefore, EOF was used to process the SPI sequences of each station, and the overall trend of drought and flood changes over time and the spatial distribution of drought and flood were analyzed. By rotating the EOF feature vector (REOF) and redistributing the variance, the principal components have more separation, and the rotative factor load vector is obtained. Each vector represents the spatial correlation distribution structure. The larger the value is, the better the correlation is, and the closer to 0 is the irrelevance, so that the results of the principal component analysis can be better explained and the area of the drought and flood is divided.

\section{Results and Analysis}

\subsection{Characteristics of Drought and Flood Time Change}

\subsubsection{SPI Comparison of Different Time Scales}

The multi-time scale characteristics of SPI can realize the monitoring of different types of droughts and floods. Synthetic application of SPI at each time scale can comprehensively monitor and evaluate droughts and floods. Figure 1 shows the evolution of SPI1 (1 month), SPI3 (3 months), SPI6 (6 months), and SPI12 (12 months) in Quanzhou from 1960 to 2014. As can be seen from the figure, since the SPI1 value is greatly affected by the monthly precipitation, it is weak in time duration and frequent changes between months, reflecting the characteristics of the monthly changes of the drought and flood. SPI3 represents short-term water deficits, which are mainly influenced by short-term (3 months) precipitation. SPI3 values fluctuate more frequently on the 0 -line, reflecting the short-term change characteristics of drought and flood. As the time scale increases, the response of SPI6 and SPI12 to short-term precipitation slows, the drought and flood changes are more stable, the cycle is more obvious, and it has a better

Table 1. SPI drought and flood level classification.

\begin{tabular}{cc}
\hline SPI Value Range & Drought and Flood Level \\
\hline SPI $\leq-2.0$ & Extremely drought \\
$-2.0<$ SPI $\leq-1.5$ & Heavy drought \\
$-1.5<$ SPI $\leq-1.0$ & Drought \\
$-1.0<$ SPI $<1.0$ & normal \\
$1.5>$ SPI $\geq 1.0$ & Waterlog \\
$2.0>$ SPI $\geq 1.5$ & Heavy Waterlog \\
$\mathrm{SPI} \geq 2.0$ & Extremely Waterlog
\end{tabular}



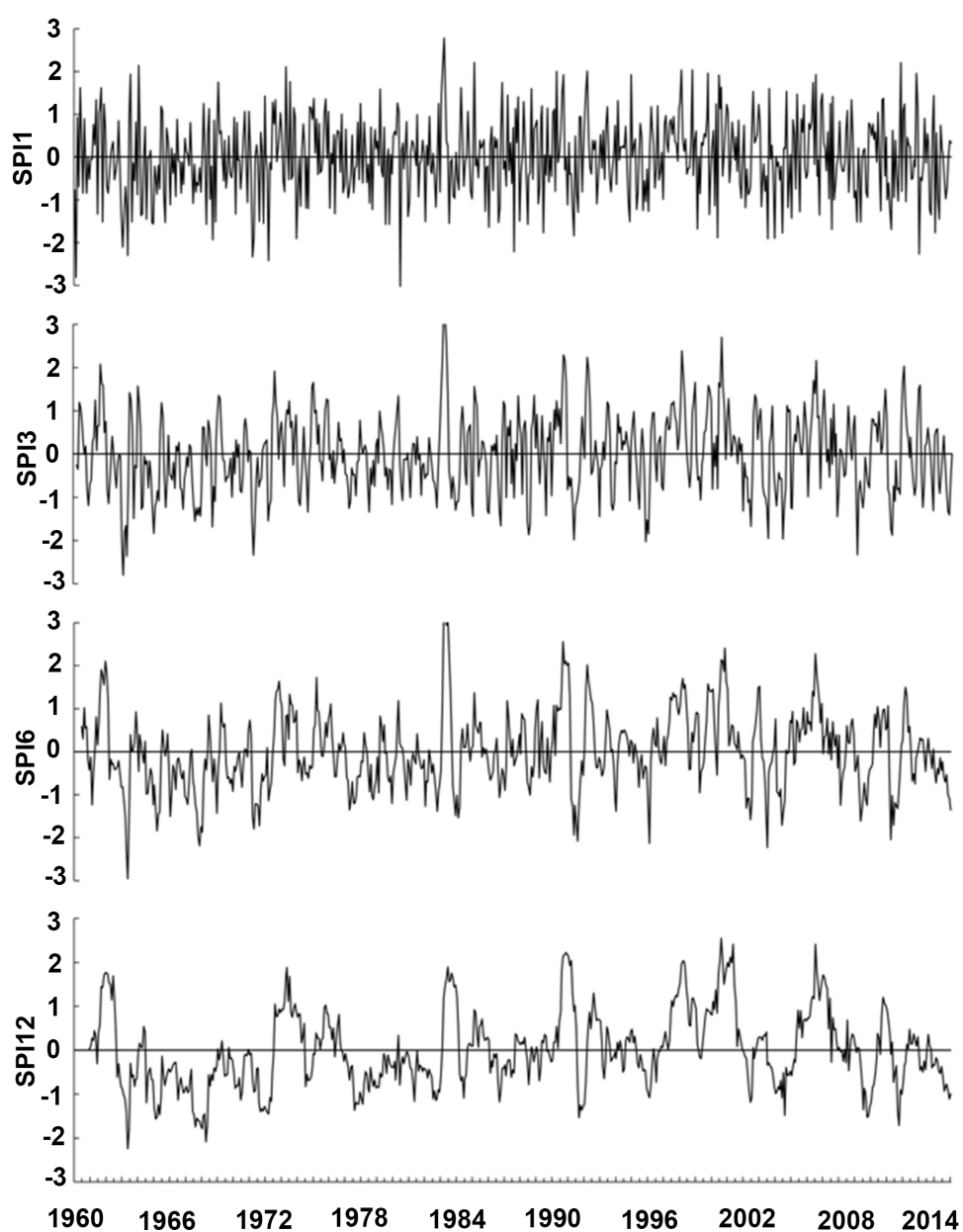

Figure 1. The evolution of SPI1, SPI3, SPI6 and SPI12 in Quanzhou from 1960 to 2014 .

reflection on the underlying soil moisture, river runoff, groundwater level and reservoir water storage capacity. The characteristics of long-term changes in drought and flood can be clearly reflected.

Taking 1963 as an example, we can see in Figure 1 that: In 1963, SPI1 showed extreme droughts in January and May, severe drought in August, moderate drought in February and April, and heavy rainfall in July, normal in March, June and September and December. SPI3 showed extreme drought in January-February and May, severe drought in March-April, mid-drought in October, Zhongyan in July-August, normal in June, September, and November-December. SPI6 showed extreme drought in April-May, heavy drought in March, moderate drought in February and June, normal in January and July-December. SPI12 showed extreme drought in May, severe drought in June, moderate drought in February and April, normal in January and July-December. It can be seen that with the change of SPI time scale, the level of droughts and floods will also change, and the onset time and end time of droughts and floods will be delayed correspondingly with the increase of SPI time scale, which fully reflects the cu- 
mulative effects of previous precipitation changes [13].

\subsubsection{Inter-Annual Variation Characteristics of Drought and Flood}

The interannual change of SPI can reflect the specific time period of drought and flood. As can be seen from the monthly changes in SPI12 in Figure 1, there were 22 droughts and 17 rainstorms in Quanzhou during the period 1960-2014. The specific time periods of frequent drought events occurred in 1963-1972, 1977-1986, and 2009-2011. Among them, extreme drought events occurred twice, that is, in May 1963 and April 1968, the SPIs were all less than -2.0. The specific time periods of frequent rainstorm incidents were 1961-1962, 1972-1975, 1990-1992 and 1997-2007, of which the extreme events occurred seven times. The results of the interannual change analysis of the drought and flood are consistent with the years of severe droughts and floods in the history of Quanzhou [14] [15] [16]. Calculating the average annual rate of SPI12 in Quanzhou is only 0.091/10a, which indicates that the overall drought in Quanzhou is weak and the precipitation is slightly increased, but the trend is not significant.

\subsubsection{Seasonal Characteristics of Drought and Flood Changes}

Related studies have shown that the time scale of 3 months SPI can be used to analyze seasonal drought, and can better represent the agricultural drought conditions [17] [18]. Therefore, the seasonal SPI index was used to analyze the seasonal variation characteristics of drought and flood in Quanzhou (Figure 2). SPI3 values in May, August, November, and February were respectively used to represent the SPI values of spring, summer, autumn, and winter.

Spring: During the period of 1960-2014, droughts and floods in Quanzhou City were characterized by periodical changes, and droughts dominated from 1960 to 1971 . There were 4 spring droughts, with an average of once every 3 years. From 1980 to 1990, the rainstorm was dominant, and there were 5 spring floods, occurring about every 2 years. SPI values were relatively stable between 1972-1979 and 1991-2014. The main years of spring drought occurred in 1963-1964, 1968, 1971, 1991, 1995, 2011 and 2014. The spring drought in 1971 was the most serious and the SPI value reached -1.90. In 1973, 1980, 1983-1984, 1990 and 2000, the year of spring floods, especially in the history of the most recent year in 1973, the SPI value reached 2.11. Calculating the linear tendency of SPI3 in spring is only $0.005 / 10 \mathrm{a}$, indicating that from the long-term trend, there is no change in spring drought and flood in Quanzhou.

Summer: Quanzhou experienced frequent droughts and floods in the summer between 1963-1973 and 1988-2008. The main summer drought years were 1967, 1978, 1988, 1991 and 2003-2004. The main summer disaster years were 1963, 1965, 1972-1973, 1993, 1997, 2000, 2006 and 2008. The summer drought in the past 55 years was the highest in 2003, the SPI value was -1.96 , the summer flood was the highest in 2006, and the SPI value was 2.17. The linear tendency of the summer SPI3 calculation was only 0.008 times per year, indicating that the 

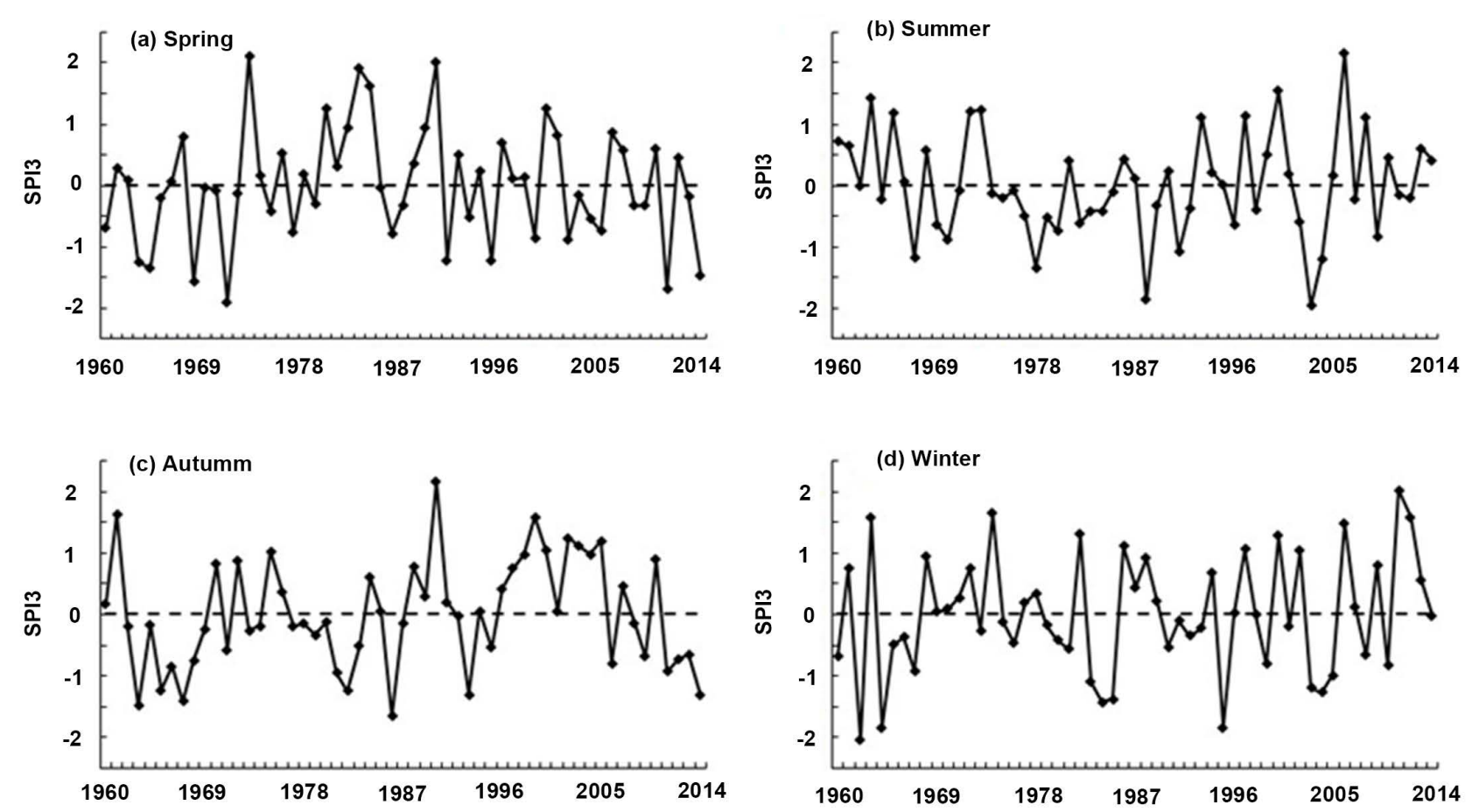

Figure 2. The change of season SPI index in Quanzhou from 1960 to 2014.

long-term change trend showed that there was no change in summer drought and flood in Quanzhou.

Autumn: The autumn drought in Quanzhou in the 1960s and the 1980s was relatively frequent. In the late 1990 s and early 21 st century, autumn quails frequently occurred, with an average of every $1-2$ years. The main autumn drought years were 1963, 1965, 1967, 1982, 1986, 1993 and 2014. The main autumn disaster years were 1961, 1975, 1990, 1999-2000, 2002-2003 and 2005. Autumn drought was the most serious in 1986, with an SPI value of -1.66 . The most serious locust plague occurred in autumn in 1990, and the SPI value reached 2.17. Calculating the linear trend rate of SPI3 in the autumn was 0.08/10a, indicating that from the long-term trend, the autumn drought in Quanzhou showed a weaker trend, but the reduction trend was not obvious.

Winter: During the period of 1960-2014, droughts and floods changed frequently in winter in Quanzhou City. Winter drought was more common in the early 1980s, and winter floods occurred frequently in the early 21 st century. The winter drought mainly occurred in 1962, 1964, 1983-1985, 1995 and 2003-2004. Winter floods mainly occurred in 1963, 1974, 1982, 1986, 1997, 2000, 2002, 2006 and 2011-2012. The year with the least precipitation in winter occurred in 1962. The SPI3 value was -2.06 , the most precipitation year appeared in 2011, and the SPI3 value was 2.03. Calculating the linear trend rate of SPI3 in winter was 0.092/10a, indicating that the winter drought in Quanzhou City showed a weaker trend of reduction, while winter precipitation slightly increased, but the trend was not significant. 


\subsection{Drought and Flood Spatial Variation}

\subsubsection{Interannual Spatial Variation of Drought and Flood}

The analysis of SPI12 using orthogonal empirical function (EOF) shows that the first two eigenvectors explain $90.9 \%$ of the total variance. After the third eigenvector, the contribution of the variance of each vector is smaller. Therefore, this article only analyzes the first two feature vectors. Figure 3 shows the distribution of the first two eigenvectors. The first feature vector accounts for the largest proportion, accounting for $77.8 \%$ of the total variance, and is the main form of spatial distribution of drought and flood in Quanzhou. As can be seen from Figure 3(a), the first feature vector values are all positive. This is obviously due to the influence of large-scale weather systems, and the overall distribution of droughts and floods is a uniform spatial pattern. It is the first type of drought and flood distribution in Quanzhou, namely the overall type. The value of each feature vector is between 0.35 and 0.44 . The positive center is located in the $\mathrm{Na}$ nan and Anxi areas in the northwest of Quanzhou. The feature vector values of Jinjiang and Chongwu in the southeast coastal area are small. This shows that the northwestern region has contributed more to the drought and flood in the city than the southeast, is the region with the highest drought and flood variability, and is a fragile drought and flood area. The second eigenvector explains $13.1 \%$ of the total variance. As can be seen from Figure 3(b), the second eigenvector value is between -0.66 and 0.52 , and the northwest and southeast are in the opposite direction. The center is located in Yongchun and Dehua in the northwest, and the negative center is in Chongwu in the southeast. This reflects the trend of drought and flood in the northwest and southeast, which is the
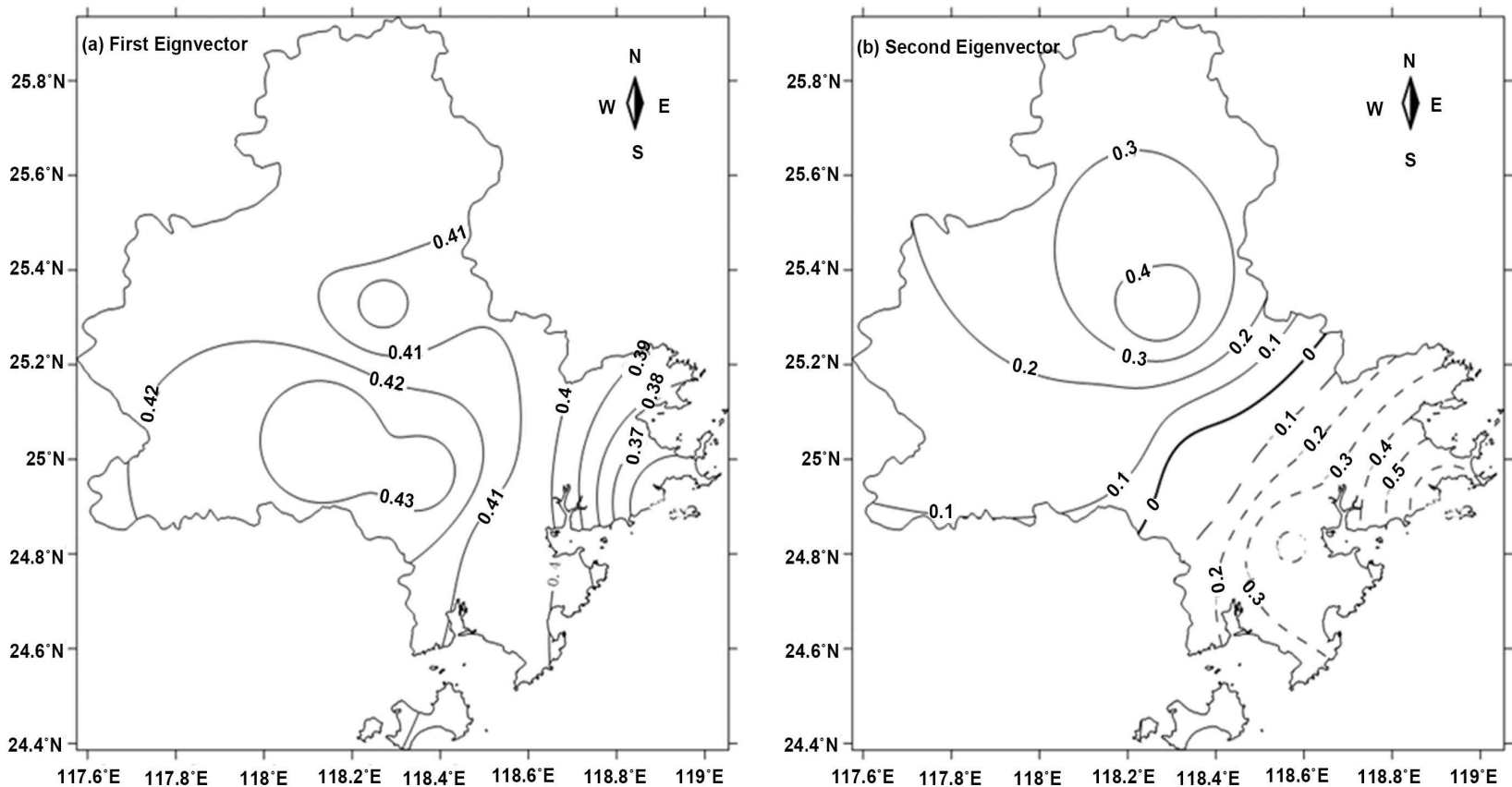

Figure 3. The first and second eigenvector fields of the EOF of the SPI12 sequence in Quanzhou from 1960 to 2014. 
second type of drought and flood distribution in Quanzhou, namely the northwest-southeast difference type. This is mainly due to the environmental factors such as geographical location and special terrain in Quanzhou, such as the northwest mountainous region is in the windward slope of the Daiyun Mountains, and the southeastern part of the coast is in the leeward slope of the Taiwan Mountains.

The first two EOF eigenvectors of SPI12 in Quanzhou were rotated by the maximum variance for factor analysis to further analyze the spatial distribution characteristics of drought and flood in Quanzhou. The absolute value large value region (|feature vector $\mid>0.8$ ) of the first orthogonal spatial module (REOF) decomposition of the first space module (Figure 4(a)) occupies most of the northwest region of Quanzhou, and the maximum positive value center is in Yongchun. This is somewhat similar to the distribution of the second mode of EOF. The large absolute value region (|feature vector $\mid>0.8$ ) of the second space model (Figure 4(b)) is located in the southeastern coastal area of Quanzhou, with the largest negative centers in Chongwu and Jinjiang, and also somewhat similar to the distribution of the second mode of EOF. According to the high load area of the first two spatial modes of REOF (load value $\geq 0.6$ ), the drought and flood in Quanzhou is divided into three regions (Figure 4(c)): The coastal areas in the southeast, the mid-level mountains in the middle, and the mountains in the northwest, including the southeast coastal areas mainly include Chongwu, Jinjiang, Shishi and most of the islands of Kinmen. The middle part of the mountainous area is mainly south of Nan'an and the northwestern part of the mountain mainly includes Dehua, Yongchun, Anxi, and northern Nan'an. This divisional result is basically consistent with the topographical features of Quanzhou City. The analysis of the linear trend rate of average SPI12 in the three regions shows that the increase trend is not obvious in the middle mountainous regions and the northwestern mountainous regions, with the central climate tendency rate being $0.054 / 10 \mathrm{a}$ and the north being $0.073 / 10 \mathrm{a}$. The southeastern coastal areas show an increasing trend, with a climatic bias of $0.137 / 10 \mathrm{a}$ (a significant test at the 0.1 level). This shows that there is no obvious trend of droughts and floods in the mountainous areas in the Mid-levels and Northwest of Quanzhou, and the drought conditions in the southeast coastal areas have been reduced.

Whether it is EOF or REOF, Yongchun is always the center point. The overall distribution of EOF and REOF is consistent.

\subsubsection{The Characteristics of Spatial Variability in Drought and Flood Seasons}

The EOF analysis was performed on SPI3 at each site in Quanzhou to obtain the distribution of the first feature vector for each season (Figure 5). The first eigenvectors of each season explained $92.4 \%, 73.2 \%, 79.9 \%$, and $84.7 \%$ of the total variance, respectively, which are sufficient to represent the main forms of the 

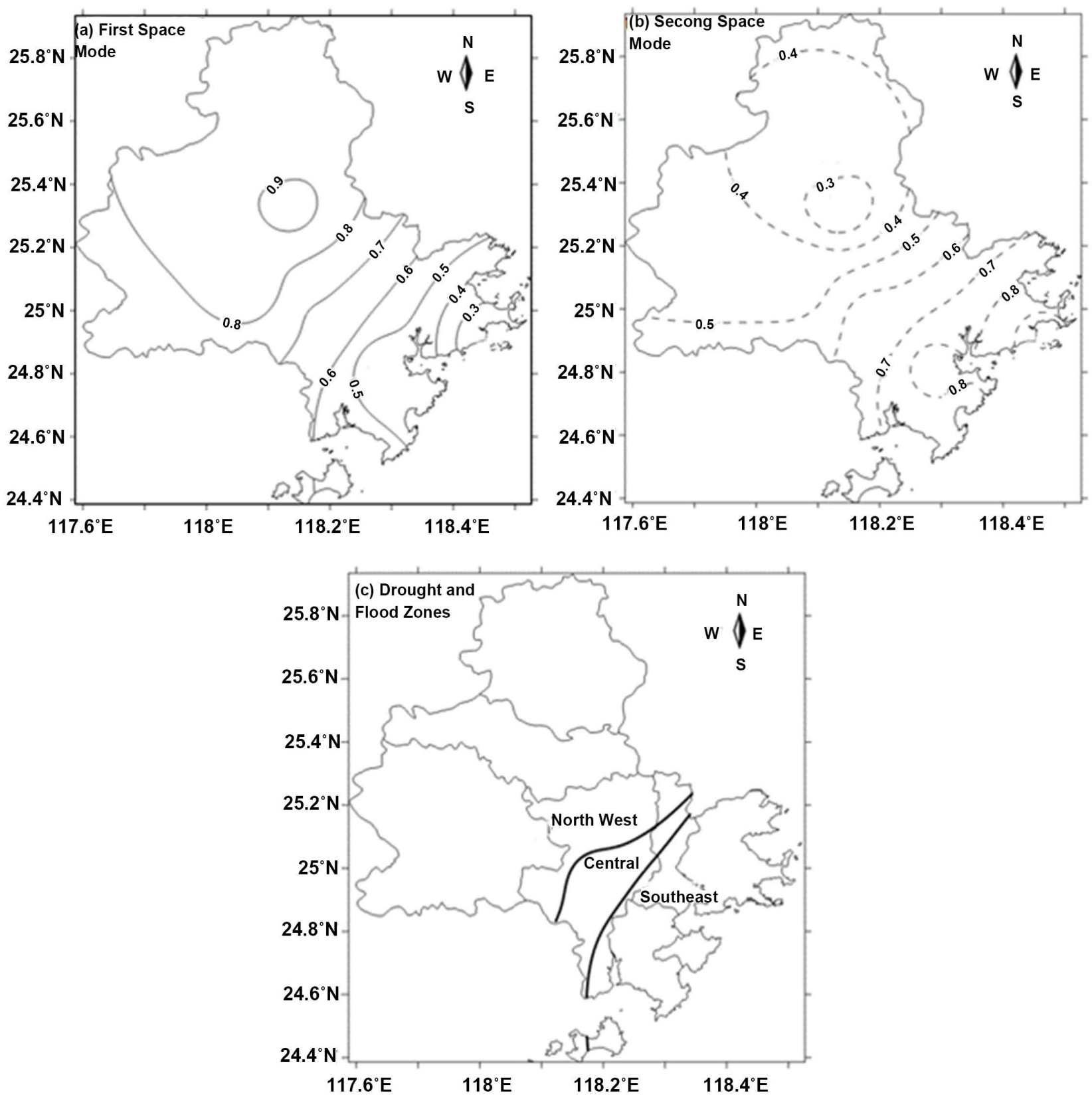

Figure 4. The first two spatial models of the annual SPI12 sequence of the REOF in Quanzhou from 1960 to 2014.

spatial distribution of drought and flood in each season, and their components are all positive. This shows that Quanzhou's precipitation in each season has a good spatial consistency. The precipitation centers of the various seasons are distributed in Nanan and Anxi areas, but the areas where the precipitation is relatively small are slightly different: Spring in Yongchun, Dehua area; summer in Chongwu, Jinjiang area; autumn in Chongwu; winter in Dehua and Chongwu. This indicates that the occurrence of rainstorms in Quanzhou in the past 55 years is similar, but the occurrence of drought in different seasons is quite different. 

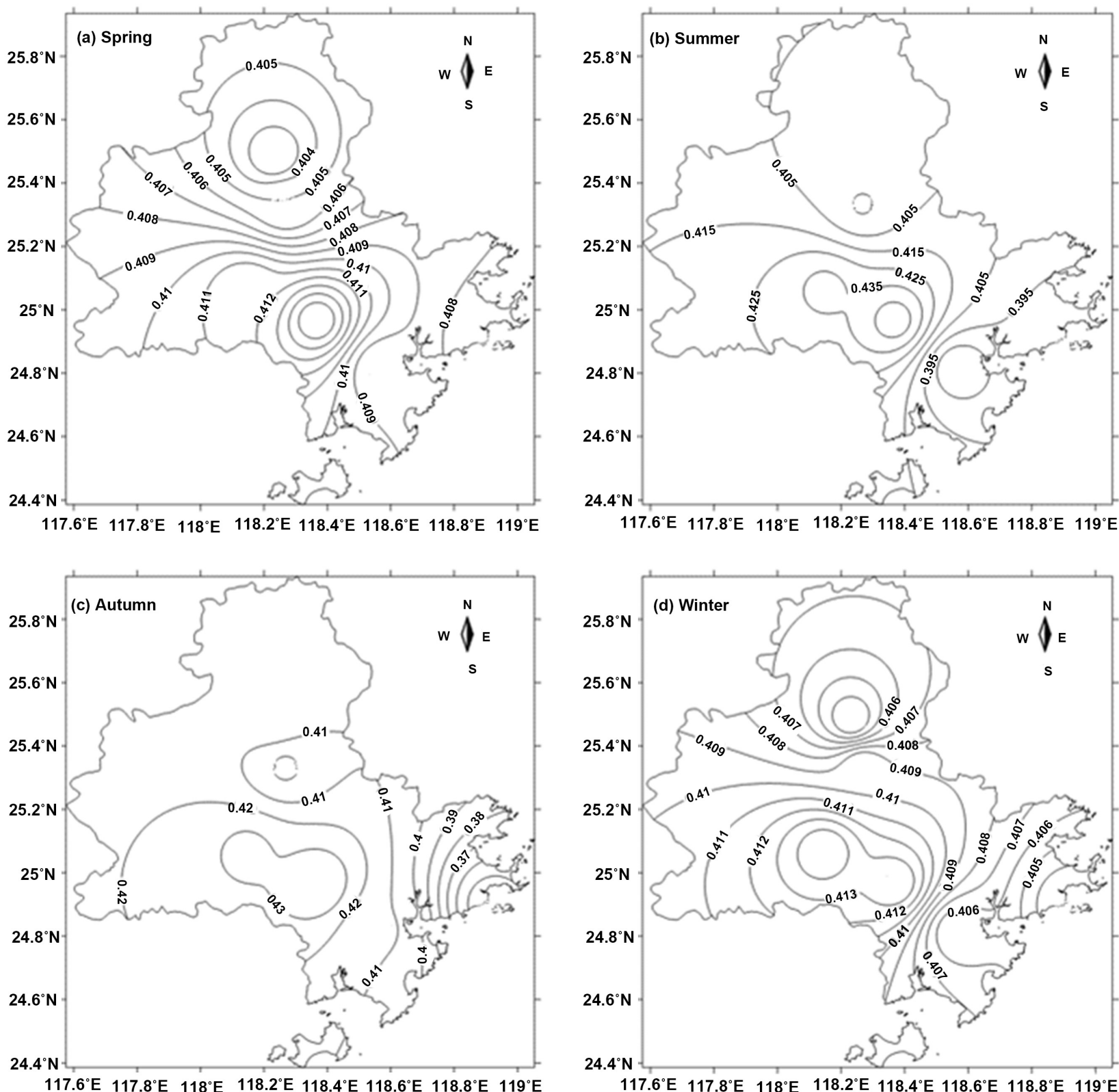

Figure 5. Distribution of EOF first feature vector field at different seasons in Quanzhou from 1960 to 2014((a) Spring; (b) Summer; (c) Autumn; (d) Winter).

\section{Conclusions}

1) Droughts and floods in Quanzhou are characterized by periodical changes. There were 22 droughts and 17 rainstorms in Quanzhou during the period from 1960 to 2014. The specific time periods for frequent drought events were 1963-1972, 1977-1986, and 2009-2011. The specific time periods of frequent rainstorm events were 1961-1962, 1972-1975, 1990-1992 and 1997-2007. The drought in Quanzhou generally showed a weaker trend, and precipitation increased slightly, but the trend was not significant.

2) During the period from 1960 to 2014, there was no change in droughts and 
floods in spring and summer in Quanzhou, but the drought in autumn and winter was decreasing, but the trend was not obvious. The spring drought occurred frequently between 1960 and 1971, and the spring flood was concentrated in 1980-1990. Summer droughts and floods were frequent between 1963-1973 and 1988-2008. The autumn drought was more common in the 1960s and 1980s, and the autumn monk occurred frequently in the late 1990s and early 2000s. Winter droughts and floods changed frequently between 1960 and 2014. Winter droughts occurred at the beginning of the 1980s and winters occurred frequently at the beginning of the 21 st century.

3) The drought and flood changes in Quanzhou have a relatively uniform trend, but they also show some differences in certain periods, which are mainly represented by the large differences in the northern mountainous area, the middle semi-mountainous area, and the southeastern coastal area. There is no obvious trend of droughts and floods in the mountainous areas in the middle and the northwest, but the drought conditions in the southeastern coastal areas have eased.

4) The precipitation in each season in Quanzhou has a good spatial consistency. The precipitation centers are in the Nanan and Anxi areas, and there are significant differences in the areas with less rainfall: spring in Yongchun and Dehua; summer in Chongwu and Jinjiang; autumn in Chongwu; winter in Dehua and Chongwu.

\section{Conflicts of Interest}

The authors declare no conflicts of interest regarding the publication of this paper.

\section{References}

[1] Koudahe, K., Kayode, A., Samson, A., Adebola, A. and Djaman, K. (2017) Trend Analysis in Standardized Precipitation Index and Standardized Anomaly Index in the Context of Climate Change in Southern Togo. Atmospheric and Climate Sciences, 7, 401-423. https://doi.org/10.4236/acs.2017.74030

[2] Moorhead, J., Marek, G., Gowda, P., Marek, T., Porter, D., Singh, V. and Brauer, D. (2017) Exceedance Probability of the Standardized Precipitation-Evapotranspiration Index in the Texas High Plains. Agricultural Sciences, 8, 783-800. https://doi.org/10.4236/as.2017.88058

[3] Zhang, Q., Ju, X.S. and Li, S.H. (1998) Comparison of Three Drought Indicators and Determination of New Indicators. Meteorological Technology, 2, 48-52.

[4] Sims, A.P., Niyogi, D.S. and Raman, S. (2002) A Dopting Drought Indices for Estimating Soil Moisture: A North Carolina Case Study. Geophysical Research Letters, 29, 1183-1186. https://doi.org/10.1029/2001GL013343

[5] Quiring, S.M. and Papakryiakou, T.N. (2003) An Evaluation of Agricultural Drought Indices for the Canadian Prairies. Agricultural and Forest Meteorology, 118, 49-62. https://doi.org/10.1016/S0168-1923(03)00072-8

[6] Livada, I. and Assimakopoulos, V.D. (2007) Spatial and Temporal Analysis of 
Drought in Greece Using the Standardized Precipitation Index (SPI). Theoretical and Applied Climatology, 89, 143-153. https://doi.org/10.1007/s00704-005-0227-z

[7] Wu, H., Hayes, M.J., Wilhite, D.A., et al. (2005) The Effect of the Length of Record on the Standardized Precipitation Index Calculation. International Journal of Climatology, 25, 505-520. https://doi.org/10.1002/joc.1142

[8] Wu, H., Svoboda, M.D., Hayes, M.J., et al. (2007) Appropriate Application of the Standardized Precipitation Index in Arid Locations and Dry Season. International Journal of Climatology, 27, 65-79. https://doi.org/10.1002/joc.1371

[9] Yuan, W.P. and Zhou, G.S. (2004) Comparative Analysis of the Application of Standardized Precipitation Index and Z Index in China. Journal of Plant Ecology, 28, 523-529. https://doi.org/10.17521/cjpe.2004.0071

[10] McKee, T.B., Doesken, N.J. and Kleist, J. (1993) The Relation of Drought Frequency and Duration to Time Scales. Proceedings of the 8 th Conference on Applied Climatology, Anaheim, California, 17-22 January 1993, 179-184.

[11] Omonijo, T. and Okogbue, E. (2014) Trend Analysis of Drought in the Guinea and Sudano-Sahelian Climatic Zones of Northern Nigeria (1907-2006). Atmospheric and Climate Sciences, 4, 483-507. https://doi.org/10.4236/acs.2014.44045

[12] Zhou, Y., Li, N. and Ji, Z.H. (2013) Spatial and Temporal Distribution of Drought in Inner Mongolia during 1981-2010 Based on SPI Index. Journal of Natural Resources, 28, 1694-1706.

[13] Che, S.J., Li, C.Q. and Shen, S.H. (2010) Spatio-Temporal Characteristics of Drought and Flood in Hebei Province in the Past 41 Years (1965-2005) Based on SPI. China Agricultural Meteorology, 31, 137-143.

[14] Song, D.Z. and Cai, S.S. (2007) China Meteorological Disasters (Fujian Vol.). Weather Press, Beijing, 392 P.

[15] Lu, S.J. and Wang, Y. (2012) Fujian Climate. Weather Press, Beijing, 520 P.

[16] Che, S.J. and Li, C.Q. (2010) Shijiazhuang's Drought Spatial and Temporal Distribution Based on Standardized Precipitation Index. Meteorological Technology, 38, 66-70.

[17] Patel, N.R., Chopra, P. and Dadhwal, V.K. (2007) Analyzing Spatial Patterns of Meteorological Drought Using Standardized Precipitation Index. Meteorological Applications, 14, 329-336. https://doi.org/10.1002/met.33

[18] Wei, F.Y. (2007) Modern Climate Statistics Diagnosis and Prediction Technology. Weather Press, Beijing, 296 P. 